\title{
ABORDAGEM DE TEMAS NO ENSINO MÉDIO: COMPREENSÕES DE PROFESSORES DE FÍSICA ${ }^{1}$
}

\author{
Roseline Beatriz Strieder* \\ Giselle Watanabe-Caramello** \\ Simoni Tormöhlen Gehlen***
}

RESUMO: Com a intenção de discutir limites e possibilidades da Abordagem Temática no contexto educacional brasileiro, neste artigo são analisadas compreensões de professores da Educação Básica sobre tal abordagem. Para tanto, foi realizado um questionário aplicado a um total de 13 professores de Física do Ensino Médio, oriundos de escolas da região metropolitana de São Paulo. Nesse questionário, foi explorada a importância que os docentes atribuem ao trabalho temático em sala de aula, os temas considerados relevantes e possíveis articulações entre os temas e os conceitos físicos. Os resultados apontam para as compreensões dos professores em três âmbitos, que articulam a abordagem de temas (i) à resolução de problemas; (ii) às discussões sobre Ciência - Tecnologia - Sociedade e (iii) ao currículo estabelecido nas escolas. Constatou-se que os professores possuem uma compreensão sobre as potencialidades da abordagem de temas no Ensino Médio, relacionando-as à resolução de problemas e à possibilidade de discussões sobre o desenvolvimento científico-tecnológico, ainda que de forma pouco crítica. Além disso, apresentam clareza, dentro de uma visão simplificadora, sobre os conteúdos que podem auxiliá-los na compreensão de determinado tema. Destaca-se a necessidade de problematizar e aprofundar as compreensões dos professores sobre a abordagem de temas, em especial, no que se refere ao papel que os temas e os conhecimentos científicos assumem no contexto escolar.

Palavras-chave: Abordagem Temática, Compreensões de Professores, Ensino de Física.

\section{THEMATIC APPROACH IN SECONDARY EDUCATION: UNDERSTANDINGS OF PHYSICS TEACHERS}

ABSTRACT: In this article, we analyze the comprehensions of teachers about the Thematic Approach. A questionnaire was conducted with 13 Physics teachers from Secondary Education. It was explored the importance that teachers attach to the thematic work in classroom, the topics considered relevant and possible connections between the themes and physical concepts. The results lead to the understandings of teachers in three spheres that articulate the Thematic Approach to (i) problem resolution, (ii) discussions of Science - Technology - Society and (iii) the established curriculum in schools. It was found that teachers have an understanding of the possibilities of Thematic Approach in Secondary Education related to problem solving and to the possibility of discussions on the scientific and technological development, even on a not very critical way; also, they have clarity, within a simplified view, of content that can assist them in understanding a given theme. There is the need to problematize and deepen teachers' understandings about the approach to themes, in particular regarding to the role that the scientific themes and knowledges take in the school context. Keywords: Thematic Approach, Understandings of Teachers, Teaching Physics. 


\section{INTRODUÇÃO}

Discussões sobre a inserção de questões socioambientais no currículo de Ciências passaram a ter um espaço maior, no contexto educacional brasileiro, a partir de 1980. Nesse período, passou-se a defender que a educação básica deveria contribuir para a formação de alunos mais conscientes de suas responsabilidades enquanto cidadãos, capazes de participar de forma inteligente e informada de decisões que envolvem tanto questões presentes na realidade próxima quanto questões de amplo alcance (KRASILCHICK, 2000).

Uma das formas de incorporar esses pressupostos no currículo escolar é por meio da abordagem de temas. No ensino de Ciências, há uma discussão sistemática em torno do fato de a organização curricular da escola básica ser estruturada por meio de temas. Um dos elementos que contribui para isso é o respaldo encontrado nos documentos oficiais, como nos Parâmetros Curriculares Nacionais (PCN) (BRASIL, 2000), PCN+ (BRASIL, 2002) e nas Orientações Curriculares para o Ensino Médio (BRASIL, 2006). Há uma sintonia entre a abordagem de temas e os documentos oficiais, principalmente no que diz respeito à organização e à contextualização dos conteúdos, à interação entre as diferentes disciplinas e à participação dos professores na elaboração do currículo, na definição de metodologias e estratégias de ensino.

Dentre os estudos que têm apresentado alternativas para a obtenção e desenvolvimento de temas, destacam-se os que se apoiam nas ideias de Paulo Freire (COELHO e MARQUES, 2007; DELIZOICOV, ANGOTTI e PERNAMBUCO, 2002; SILVA, 2004); os que envolvem a perspectiva vygotskyana (MALDANER, 2007); os que têm como foco os temas propostos pelos PCNs (REIS, SOUZA e BISCH, 2007) e os temas com enfoque Ciência - Tecnologia - Sociedade (CTS) (AULER, 2002; SANTOS e MORTIMER, 2000).

Na perspectiva defendida por Delizoicov, Angotti e Pernambuco (2002), a estruturação do conteúdo programático por meio de temas é denominada de Abordagem Temática. Essa proposta se constitui em uma perspectiva curricular em que são identificados temas com base nos quais se selecionam os conteúdos científicos necessários para compreendê-los. Embora Delizoicov, Angotti e Pernambuco (2002) destaquem a perspectiva de Paulo Freire, os autores não consideram que uma Abordagem Temática se reduz apenas a ela, podendo ser também explorada no contexto de outros referenciais, como os citados anteriormente.

Um dos focos de interesse dos estudos que investigam atividades didático-pedagógicas centradas na abordagem de temas refere-se à formação dos professores, mais especificamente ao levantamento das compreensões dos docentes. Nesse sentido, destacam-se os trabalhos de Coelho e Marques (2007), Forgiarini e Auler (2009) e Lindemann et al. (2009), que apontam que as compreensões dos professores se configuram como obstáculos para o desenvolvimento de abordagens temáticas, principalmente porque muitos não reconhecem os temas como um problema social, mas como uma forma de abordar conceitos científicos, e porque muitos assumem o papel de meros repassadores e reprodutores das informações veiculadas pela mídia, 
alimentando mitos e promessas em relação aos temas, a exemplo da perspectiva salvacionista $^{2}$ atribuída à ciência-tecnologia (AULER, 2002). Em virtude disso, esses estudos apontam a necessidade de haver discussões que buscam um olhar mais crítico, por parte dos docentes, para as questões científico-tecnológicas, sobretudo em processos de formação inicial e continuada de professores.

Nessa mesma linha, Strieder e Kawamura (2009), ao analisarem trabalhos centrados na perspectiva CTS, apontam que uma formação de professores coerente com essa proposta vem sendo reivindicada por pesquisadores da área de Ensino de Ciências. Apesar disso, as autoras sinalizam que as investigações abarcam um tema em específico e raramente envolvem professores em exercício e que não possuem vínculo com instituições de pesquisa.

Considerando esse panorama, é de suma importância ampliar as pesquisas que buscam compreender como professores de Física em exercício, desvinculados de projetos e propostas de pesquisa, compreendem a abordagem de temas em sala de aula. Entendemos que a eficácia das implementações de propostas inovadoras, sejam elas temáticas ou não, depende também dos professores, de seu engajamento, suas atitudes e compreensões (CARVALHO, 2007).

Dessa forma, investigamos compreensões de professores de Física do Ensino Médio, vinculados à rede pública e particular da região metropolitana de São Paulo, sobre a abordagem de temas em sala de aula. Exploramos aspectos como a importância que os docentes atribuem ao trabalho temático em sala de aula, os temas considerados relevantes e as possíveis articulações entre os temas e os conceitos físicos. Esses aspectos relacionam-se a duas questões de investigação: por que ensinar na perspectiva da Abordagem Temática? O que ensinar nessa perspectiva? Com isso, buscamos mapear limites e possibilidades das implementações de temas em sala de aula, com o intuito de apontar caminhos para o processo de formação inicial e continuada.

\section{A PESQUISA}

A pesquisa foi realizada com 13 professores de escolas públicas e particulares que trabalham com a disciplina de Física, no Ensino Médio, na região metropolitana de São Paulo, Brasil. Eles foram selecionados por terem supervisionado licenciandos em Física de uma Instituição Federal de São Paulo durante o estágio obrigatório, em que foram desenvolvidas atividades centradas na Abordagem Temática. Cabe destacar que esses professores não estão vinculados a projetos dessa instituição, assim como também não possuem qualquer relação com outros projetos de órgãos governamentais ou particulares, sendo a escolha deles realizada pelos próprios estagiários, em geral, em virtude da localização da escola.

Em outras palavras, o critério para seleção dos professores foi o fato de estarem atuando na educação básica, não participarem de projetos de pesquisa e conhecerem a proposta da abordagem de temas, ainda que indiretamente, por meio do trabalho desenvolvido pelos estagiários. 
As compreensões desses professores foram investigadas a partir de um questionário composto por três questões, selecionadas por permitirem uma análise acerca da forma como eles entendem o trabalho com temas, em especial, as justificativas para se trabalhar nessa perspectiva e o papel que os temas, articulados aos conhecimentos científicos, podem assumir no contexto escolar.

1. Para você, trabalhar conteúdos de Física, no Ensino Médio, a partir de temas sociais/ambientais irá contribuir para a formação dos estudantes? Por quê?

2. Considerando a realidade dos alunos, quais temas você entende que poderiam ser discutidos em sala de aula (questões sociais, ambientais etc.)?

3. Quais conhecimentos de Física, na sua compreensão, estão relacionados a esses assuntos?

As informações fornecidas pelos professores nesse questionário foram analisadas por meio dos princípios da Análise Textual Discursiva (MORAES e GALIAZZI, 2007), que tem sido utilizada na pesquisa em Educação em Ciências como um encaminhamento metodológico (MASSENA, 2010; LINDEMANN et al., 2009; TORRES et al., 2008; CIRINO e SOUZA, 2008; ROSA e MARTINS, 2007). Seguindo essa dinâmica, foram realizados os seguintes procedimentos: unitarização - ocorreu a fragmentação dos textos elaborados através das respostas dos professores sobre o questionário, originando, assim, unidades de significado; categorias temáticas - as unidades de significado foram agrupadas segundo suas semelhanças semânticas e sob um olhar teórico, envolvendo especialmente os pressupostos de Freire (FREIRE, 1987), da Abordagem Temática (DELIZOICOV, ANGOTTI e PERNAMBUCO, 2002) e do enfoque CTS (AULER, 2002; SANTOS e MORTIMER, 2000); comunicação - elaboração de textos descritivos e interpretativos (metatextos) acerca das categorias temáticas. Vale destacar que na organização das categorias temáticas, segundo Moraes e Galiazzi (2007, p.28), não há um vácuo teórico, pois “toda categorização implica uma teoria. O conjunto de categorias é construido a partir desse referencial de abstração que o suporta. Esse olhar teórico pode estar explícito ou não, ainda que seja desejável sua explicitação".

Também é importante ressaltar que nessa dinâmica as unidades de significado - extratos das respostas dos professores sobre o questionário - podem estar presentes em mais de uma categoria, ainda que com sentidos diferentes, uma vez que "uma mesma unidade pode ser lida de diferentes perspectivas, resultando em múltiplos sentidos, dependendo do foco ou da perspectiva em que seja examinada" (MORAES e GALIAZZI, 2007, p. 27). Assim, alguns extratos das respostas dos professores sobre o questionário foram abordados em mais de uma categoria.

A seguir, discutimos as três categorias de análise: (i) abordagem de temas e resolução de problemas; (ii) abordagem de temas e discussões sobre CTS; (iii) abordagem de temas e o currículo estabelecido. A identificação dos professores questionados deu-se pelo sistema alfanumérico P1, P2,..., Pn, resguardando sua identidade. 


\section{Abordagem de temas e a resolução de problemas}

Um dos elementos a ressaltar na análise refere-se à relação entre a abordagem de temas e a resolução de problemas. Nesse sentido, destacam-se, em um primeiro momento, as compreensões de P13 e P9, que atribuíram ao trabalho com temas a possibilidade de discutir com os alunos como o conhecimento científico pode ser utilizado para compreender e resolver problemas:

\footnotetext{
Atualmente a Física está presente na vida de todos, dessa forma, temas atuais ligados a questões presentes do cotidiano ajudam e muito na sua formação. Temas como a TV digital, telecomunicações, rendimento de aparelhos elétricos, fontes de energia e outros, trazem ao aluno a oportunidade de vivenciar situações onde seu conbecimento em Física poderá ajudá-lo a ver e resolver situacões com um pensamento lógico e cientifico. (P13 - grifo nosso)

[...] é uma maneira interessante de se trabalhar, pois podemos mostrar como a Física pode ajudar a solucionar um problema ou mostrar que caso não haja uma solução imediata, pelo menos podemos mostrar a explicação física para um dado problema. (P9 - grifo nosso)
}

Essas passagens apresentam indícios de que P13 e P9 compreendem que na perspectiva da Abordagem Temática o conhecimento científico é um meio ou um instrumento necessário para o entendimento de questões mais amplas (temas ou problemas), que constituem os objetos de conhecimento, como proposto por Delizoicov, Angotti e Pernambuco (2002). Esses autores, tendo como referência as ideias de Bachelard (1996), concordam com a concepção de que o conhecimento se origina a partir de questionamentos, na busca de soluções para problemas consistentemente formulados. Coerentes com esses pressupostos, esses autores, ao fazerem uma releitura do trabalho de Paulo Freire para espaço da educação formal, particularmente para o ensino de Ciências, apontam que durante o desenvolvimento de um tema é fundamental que sejam abordadas situações-problemas com as quais os alunos se envolvam, desenvolvendo competências, atitudes e valores necessários para a resolução do tema em questão.

Nesse sentido, como destacado por Gehlen (2009), é importante atentar para a natureza do problema, uma vez que o mesmo assume uma dimensão epistemológica e é entendido como o ponto de partida da obtenção e desenvolvimento de temas. No caso da Abordagem Temática, a autora destaca que cabem problemas que apresentam uma relação com a realidade em que se insere a comunidade escolar, como aqueles que são manifestações de contradições locais (FREIRE, 1987) presentes na vivência dos sujeitos.

Sendo assim, é importante observar que P9, embora articulando os temas à resolução de problemas, não esclarece a qual tipo de questão está se referindo, ou seja, não explicita a qualidade do problema a ser abordado. Seriam contradições sociais, associadas à realidade dos alunos? Ou seriam dificuldades encontradas na linha da Resolução de Problemas (PEDUZZI e PEDUZZI, 2001)? O fato de P9 não ter citado exemplos de temas e de problemas pode estar associado a sua pouca clareza quanto à importância da abordagem de questões 
pertencentes à realidade dos alunos, ou seja, que façam sentido para eles, como defendido pela Abordagem Temática.

Porém, na resposta de P13, apresentada anteriormente, e de outros professores, por exemplo, P12 e P10, é possível identificar uma clareza maior quanto à natureza das questões, principalmente no momento em que os professores são questionados sobre os possíveis temas a serem abordadas em sala de aula. Eles apresentaram uma preocupação em estabelecer vínculos com a realidade a que pertencem, professores e alunos, como ilustrado nas passagens de P12 e P10:

Poderia ser discutida a questão da poluição dos carros. Como quais eram os niveis de poluição antes de os carros surgirem, e depois dos carros com motor. O que poderia ser feito para amenizar esses efeitos, etc. (P12 - grifo nosso)

[...] No terceiro colegial, poderíamos tratar dos "gatos" feitos por muitos moradores na rede elétrica de seus bairros. Para o segundo ano, uma possibilidade é tratar mudancas climáticas utilizando a termodinâmica e conceitos de transmissão de calor. Para o primeiro ano, poderíamos optar por conceitos de velocidade média e instantânea faz̧endo uma abordagem temática e relacionando com o trânsito, suas implicações e acidentes envolvidos. Nas três propostas é possivel incluir discussões sociais e ambientais. (P10 - grifo nosso)

Ainda que P10 e P12 defendam uma temática voltada à realidade dos alunos, não é possível determinar, a partir de suas falas, até que ponto a discussão dessas questões será permeada por um olhar crítico e transformador, principalmente porque os temas citados fazem parte de um contexto e de uma realidade mais ampla, a cidade de São Paulo, Brasil. Além disso, cabe ressaltar que, pela natureza das questões levantadas (poluição, irregularidades nas instalações, trânsito, etc.), há indícios de que esses professores se pautaram em informações veiculadas pela mídia, o que pode ser considerado como pertencente a uma realidade mais ampla, na perspectiva da Abordagem Temática. Contudo, nesse caso, é importante que haja um olhar crítico para essas questões, para que elas sejam problematizadas e aprofundadas.

Nesse sentido, destacamos a fala de P11, que atribui ao trabalho com temas a possibilidade de promover uma educação que contribui para a formação de cidadãos mais críticos e informados a respeito da realidade na qual se encontram:

[...] poderá contribuir para a formação do aluno, no sentido em que buscará torná-lo mais crítico on pelo menos fazer com que ele conbeca o entorno da escola e saiba quais os principais problemas ali existentes. (P11 - grifo nosso)

A expressão de P11 está em sintonia com o pensamento de Freire (1987) por fazer referência à questão da criticidade e conscientização, por parte dos alunos, perante os problemas pertencentes a sua realidade. Para Freire (1987), a consciência relaciona-se ao olhar mais crítico possível sobre a realidade, para que seja possível conhecê-la e agir sobre ela. Dessa forma, o autor defende que a educação precisa estimular a reflexão sobre a realidade, contribuindo, assim, para que a sociedade participe de forma consciente da construção de sua própria história. Coerente com essa 
perspectiva educacional, dentre os critérios para a definição de temas, Freire (1987) propõe o processo de Investigação Temática ${ }^{3}$, em que a obtenção de Temas Geradores se dá a partir de situações significativas que os sujeitos vivenciam.

Como é possível identificar na citação acima, P11 reconhece na Abordagem Temática uma possibilidade de os alunos refletirem sobre a realidade na qual se encontram, indicando que esse pode ser o ponto de partida para a formação de cidadãos críticos. Contudo, esse professor apenas identifica a necessidade de refletir, mas não sinaliza a possibilidade de intervenção na realidade, aspecto central da proposta freireana. Para Freire (1987, p. 80), "a educação problematizadora de caráter autenticamente reflexivo, implica um constante ato de desvelamento da realidade, [...] busca a emersão das consciências, de que resulte sua inserção crítica na realidade".

Em síntese, destaca-se que alguns professores vinculam a abordagem de temas à resolução de problemas, o que poderia indicar, em uma primeira análise, que eles compreendem que essa abordagem possibilita a realização de mudanças na realidade, ou seja, compreendem o caráter transformador dessa proposta. Contudo, ao analisarmos a natureza dos temas citados e as questões que os professores sugerem trabalhar, constata-se certo distanciamento dos docentes em relação à realidade na qual se encontram, além de uma aproximação maior com uma realidade que pode ser considerada mais ampla, como, por exemplo, a veiculada pela mídia. No entanto, cabe destacar que o importante, na perspectiva da Abordagem Temática, é que os temas tenham algum significado para os estudantes e sejam problematizados, para que despertem neles a necessidade de outros conhecimentos necessários para compreender o tema em questão. Assim, o estudo aponta para a necessidade de haver uma problematização e um aprofundamento dos temas e das compreensões dos professores sobre a abordagem de temas, para que eles não se pautem unicamente em informações como as veiculadas pela mídia.

\section{Abordagem de temas e as relações entre CTS}

Outro aspecto presente na fala dos professores diz respeito à articulação entre a Abordagem Temática e discussões envolvendo questões científico-tecnológicas. Nesse sentido, destaca-se, novamente, a resposta de P13, que evidencia a utilização de aparatos tecnológicos, como, por exemplo, a TV digital e os aparelhos elétricos, para exemplificar a articulação entre os conteúdos de Física e o cotidiano dos alunos.

Atualmente a Física está presente na vida de todos, dessa forma temas atuais ligados a questões presentes do cotidiano ajudam e muito na sua formação. Temas como a TV digital, telecomunicações, rendimento de aparelhos elétricos, fontes de energia e outros, trazem ao aluno a oportunidade de vivenciar situações onde seu conhecimento em Física poderá ajudá-lo a ver e resolver situações com um pensamento lógico e cientifico. (P13)

Essa articulação entre conteúdos de Física e aparatos tecnológicos é proposta desde 1984, pelo Grupo de Reelaboração do Ensino de Física (GREF), coordenado por docentes do Instituto de Física da Universidade de São Paulo (IFUSP). 
Esse grupo elaborou uma proposta de ensino de Física, para o Ensino Médio, que apresenta o conteúdo a partir de elementos vivenciais dos estudantes, dentre os quais há uma forte presença de equipamentos tecnológicos usuais, como, por exemplo, o motor a combustão, a máquina fotográfica e o chuveiro elétrico.

Atualmente, a utilização de questões tecnológicas vem ganhando um novo incentivo, na medida em que a tecnologia é entendida, nos PCNs, como parte integrante da área de Ciência da Natureza. Dessa forma, os estudos brasileiros em torno dessa temática têm aumentado, dentre os quais ganham destaque os balizados pela perspectiva CTS (SANTOS e MORTIMER, 2000; AULER, 2002).

Contudo, é importante destacar que nessa perspectiva não basta que o professor reconheça a importância de vincular o conhecimento científico a aparatos tecnológicos, é preciso que ele avance em relação ao significado da ciência e da tecnologia na sociedade atual (BAZZO, 1998). Como destacado por García, Cerezo e Luján (1996), o movimento CTS, desde sua origem em meados do século XX, em países da América do Norte e Europa, vem defendendo a necessidade de discussões sobre a relação da ciência e da tecnologia com o desenvolvimento da vida social, reivindicando uma tomada de consciência com relação aos problemas ambientais, éticos e de qualidade de vida relacionados às contribuições dos avanços científicos e tecnológicos.

Nessa direção está o professor P7, que atribui à abordagem de temas sociais e ambientais uma possibilidade de discutir os impactos da ciência e da tecnologia na sociedade:

[.. a ciência, além de se preocupar com novas tecnologias e descobertas, deve se preocupar com o impacto que essas novas tecnologias podem trazer ao serem lançadas em nosso ambiente. Devemos nos preocupar com a formação intelectual e social de todos; assim podemos contribuir para uma melhor convivência em nossa sociedade. (P7)

A expressão de P7 aponta na direção de uma visão de ciência não neutra, ao mencionar que ela deve se preocupar com o impacto ambiental causado. Contudo, não faz referência aos antecedentes sociais, ou seja, à maneira como a sociedade influencia o desenvolvimento científico-tecnológico. O reconhecimento dessa dimensão, dos antecedentes sociais do desenvolvimento científico-tecnológico, é entendido como o ponto de partida para discussões sobre CTS e o que permite um olhar crítico, como destacado por Fourez (2003),

A compreensão desta implicação do social na construção das tecnologias torna possível um estudo crítico destas, como o fazem os trabalhos de avaliação social das tecnologias. Uma formação para a negociação com as tecnologias deve tornar os alunos capazes de analisar os efeitos organizacionais de uma tecnologia. (FOUREZ, 2003, p.10)

Nessa mesma linha, Delizoicov, Angotti e Pernambuco (2002) defendem a necessidade de se discutir as implicações da ciência e da tecnologia na sociedade e o direcionamento dado à atividade científico-tecnológica para, assim, propiciar uma 
melhor compreensão do balanço benefício-malefício dessa relação. Para os autores:

[...] a ação docente buscará construir o entendimento de que o processo de produção do conhecimento que caracteriza a ciência e a tecnologia constitui uma atividade humana, sócio-historicamente determinada, submetida a pressões internas e externas, com processos e resultados ainda pouco acessíveis à maioria das pessoas escolarizadas, e por isso passíveis de uso e compreensão acríticos ou ingênuos; ou seja, é um processo de produção que precisa, por essa maioria, ser apropriado e entendido (DELIZOICOV, ANGOTTT, PERNAMBUCO, 2002, p.34).

Os autores defendem um ensino/aprendizagem de ciência e tecnologia como cultura, no qual o conhecimento científico-tecnológico deve ser apropriado criticamente pelos alunos. Para que isso seja possível, Auler e Delizoicov (2006) defendem a relação entre o pensamento de Freire e os pressupostos do enfoque CTS, no sentido de que há necessidade da superação da suposta neutralidade da CiênciaTecnologia, o que se aproxima do que Freire (1987) denominou de consciência real efetiva ${ }^{4}$. Essa superação se dá mediante a aproximação entre Freire-CTS, expressa por meio da leitura crítica da realidade e a compreensão crítica sobre as interações entre CTS, o que configura a consciência máxima possível ${ }^{5}$ (FREIRE, 1987).

Ainda na perspectiva das discussões sobre CTS, é possível identificar outras limitações nas relações estabelecidas pelos professores, principalmente no momento de articulação entre o tema e os conceitos científicos. Por exemplo, ao vincular o tema poluição atmosférica com aspectos conceituais, o professor P12 procura explicar o funcionamento dos motores de automóveis, indicando que em seu entendimento isso é suficiente para compreender o problema.

Pode-se falar da parte mecânica do motor, como os processos de admissão, compressão, combustão e exaustão. A questão das transformações de energia no motor, a existência de carro movido a ar comprimido, o que mudaria ou não, a questão da dilatação do combustivel de acordo com a mudança de temperatura. (P12)

Certamente, o funcionamento dos aparatos tecnológicos é importante e poderia ser um ponto de partida a ser utilizado, contudo, como já destacado anteriormente, para uma efetiva compreensão do tema é necessário que sejam tratadas questões mais amplas, como, por exemplo, as causas e as consequências da fabricação e utilização de determinadas tecnologias. Nesse sentido, torna-se necessário discutir, também, as esferas produtiva, organizacional e cultural (PACEY, 1990) relacionadas à tecnologia em questão.

Além do funcionamento de aparatos tecnológicos, é preciso aprender a avaliar as implicações, o custo-benefício e, principalmente, descobrir/estimar o irreversível a que tais usos nos conduzirão (BAZZO, 1998). Ou seja, é preciso compreender a questão tecnológica como um todo, com suas implicações éticas, políticas, econômicas, ambientais, culturais e sociais. Na perspectiva do movimento CTS, não se trata de ir contra ou a favor do desenvolvimento tecnológico, mas de compreender seu significado, ou seja, suas relações e implicações na vida humana. 
Ao vincular o tema apenas com aspectos conceituais, constatamos que o professor P12 apresenta uma concepção de alfabetização científico-tecnológica muito próxima do que Auler (2002) denomina de reducionista. Essa concepção consiste em uma prática pedagógica conservadora, reduzida ao ensino de conceitos e/ou de artefatos tecnológicos e científicos em uma dimensão apenas técnica e utilitarista. O autor, no âmbito do movimento CTS, defende uma perspectiva ampliada de alfabetização científico-tecnológica, baseada nos pressupostos de Freire (1987), que busca contribuir para uma leitura crítica da realidade.

Dessa forma, ainda que os professores reconheçam a possibilidade de discussões sobre CTS no âmbito da abordagem de temas, constatou-se que suas concepções precisam ser problematizadas. Como argumentado anteriormente, para haver uma compreensão crítica sobre CTS, precisamos ir além das discussões apresentadas pelos professores, buscando, principalmente, superar a concepção reducionista da alfabetização científico-tecnológica.

\section{Abordagem de temas e os currículos estabelecidos}

No que se refere à articulação do tema ao conteúdo e conceitos de Física, as relações estabelecidas pelos professores indicam que eles têm clareza sobre os possíveis conceitos que podem ajudar ao tratar o tema escolhido, como é possível identificar nas falas de P6, P7 e P10:

\footnotetext{
Com relação ao consumo de energia poderiamos pegar um gancho ao estudarmos energia, potência de uma máquina e potência elétrica. Quanto ao desenvolvimento tecnológico, vários assuntos de física estão relacionados, como, por exemplo, o eletromagnetismo, o estudo das ondas etc. (P6)
}

Trânsito: cinemática escalar, cinemática vetorial, aceleração escalar, quantidade de movimento e colisões (dentro de tais conteúdos abordar a questão do trânsito caótico das grandes capitais e, ainda, a questão da necessidade da direção defensiva para evitar acidentes e a embriaguez ao volante). - Ligações clandestinas: eletricidade em geral. - Lixo e ocupação de áreas de mananciais: hidrostática em geral. (P7)

No primeiro ano, abordariamos cinemática, localização geográfica para determinar posicionamento $e$ velocidades, a questão das lesões que os acidentes causam com o enfoque biológico e, por fim, indices de mortalidade relacionados ao trânsito, no que tange à Geografia. No segundo e no terceiro ano, poderiam ser abordados calorimetria, efeito joule, consequências para os seres vivos quando submetidos a variações climáticas ou a choques elétricos, correntes de conveçãa no planeta terra, a questão da geração e transmissão de energia elétrica, junto com os riscos que existem ao se subir num poste para tentar fazer uma ligação clandestina. (P10)

Apesar disso, P6, P7 e P10 condicionam o tema aos conceitos físicos, isto é, a partir de determinados conceitos selecionam-se os temas. Isso está explícito na fala de P10, quando sinaliza os temas que podem ser trabalhados a partir dos conteúdos referentes a cada nível do Ensino Médio. Esse aspecto foi observado, também, em outras respostas: 
Há vários [temas], para cada realidade poderá ser discutida uma fisisca aplicada. Exemplo: Aquecimento aquecimento global; velocidade, quantidade de movimento, energia - acidentes de carro; ação e reação - pipas, aviões, helicópteros, etc.; eletricidade em casa, etc. (P4)

Esse enquadramento depende da série sobre o qual estamos falando. No terceiro colegial, poderíamos tratar dos "gatos" feitos por muitos moradores na rede elétrica de seus bairros. Para o segundo ano, uma possibilidade é tratar mudanças climáticas utilizando a termodinâmica e conceitos de transmissão de calor. Para o primeiro ano, poderíamos optar por conceitos de velocidade média e instantânea fazendo uma abordagem temática e relacionando com o trânsito, suas implicaçōes e acidentes envolvidos. Nas três propostas é possivel incluir discussões sociais e ambientais. (P10)

Nessas passagens é possível identificar que os temas sugeridos por P4 e P10 partem dos conceitos presentes nos livros didáticos e nos currículos de Física. Isso indica que os professores estão muito arraigados ao ensino baseado na Abordagem Conceitual, que segundo Delizoicov, Angotti e Pernambuco (2002), volta-se a uma perspectiva curricular cuja lógica de organização é estruturada pelos conceitos científicos, com base nos quais se selecionam os conteúdos de ensino.

Essa dificuldade apresentada pelos professores também foi constatada por Lindemann et al. (2009), quando alguns docentes afirmam que um determinado tema necessita ser "encaixado" no currículo, configurando uma concepção linear e fragmentada dos conteúdos, como a presente na maioria dos livros didáticos brasileiros.

A proposta da Abordagem Temática vem justamente romper com essa lógica que organiza os currículos escolares tomando como referência os conceitos científicos. Contudo, como destacado por Delizoicov, Angotti e Pernambuco (2002), pensar os currículos das diferentes disciplinas na perspectiva da Abordagem Temática constitui-se um desafio, pois representa uma ruptura com uma lógica já estabelecida a longa data e que é hegemônica no atual sistema de ensino. Uma ruptura semelhante é proposta nos PCNs + (BRASIL, 2002) que estruturam as disciplinas em torno de eixos temáticos. Para a disciplina de Física, no Ensino Médio, são privilegiados seis temas: Movimentos: variações e conservações; calor, ambiente e usos de energia; som, imagem e informação; equipamentos elétricos e telecomunicações; matéria e radiação; universo, Terra e vida.

Além disso, esses mesmos professores (P6, P7, P4 e P10), por parecerem estar presos ao currículo estabelecido, pouco mencionam sobre os aspectos sociais, políticos e econômicos relacionados aos temas. Essa postura pode contribuir para um ensino cada vez mais distante da realidade discente. Nesse sentido, tal como aponta García (1998), é importante que o ensino integre os conhecimentos de diferentes esferas (científico, escolar e cotidiano), tomando o conhecimento cotidiano enquanto um conhecimento extremamente contextualizado. Segundo o autor, as situações advindas do cotidiano requerem uma resposta mais complexa do indivíduo. Nesse sentido, a relação do conhecimento no âmbito escolar não deve ficar restrita ao currículo, mas às esferas de conhecimento, de modo que o tema ou assunto possa estabelecer relações com outras formas de conhecimentos. 
Nas falas dos professores também foi possível perceber a necessidade de estabelecimento de relações com outras disciplinas. Por exemplo, para P12 as questões que envolvem implicações na saúde e agentes poluidores presentes na atmosfera (gás carbônico, metano, material particulado etc.) são apontadas como assuntos referentes aos professores de outras disciplinas.

A quimica pode entrar para explicar, por exemplo, o que faz o conversor catalítico no carro, tratar das questões ambientais, de liberação de gases poluentes pelos carros... O professor de biologia poderia tratar das questões de saúde pública, como o que afeta nossa saúde toda essa liberação de gases poluentes pelos automóveis. (P12)

Essa relação pode estar associada à dificuldade que os professores apresentam em visualizar conteúdos diferentes dos presentes nos livros didáticos. Por outro lado, isso aponta para o reconhecimento da necessidade de uma abordagem interdisciplinar. Esse reconhecimento da interdisciplinaridade também está presente no entendimento de P10 e P8:

No primeiro ano, abordaríamos cinemática, localização geográfica para determinar posicionamento $e$ velocidades, a questão das lesões que os acidentes causam com o enfoque biológico e, por fim, indices de mortalidade relacionados ao trânsito, no que tange à Geografia. (P10)

Sobre a água e o lixo [...] neste caso será trabalhado conteúdos de Física e Geografia, ciclo da água, a geografia de um lugar, a importância de aterros, reciclagem, poluição do lençol freático, mananciais, rios e etc... (P8)

Há indicativos, nas falas de P10 e P8, de que a interdisciplinaridade se constitui fundamental para o desenvolvimento de temas em sala de aula, aspecto que está em consonância com os PCNs, que apontam a necessidade de várias áreas do conhecimento para a compressão de uma determinada problemática (BRASIL, 2000). Para os PCNs, a interdisciplinaridade não significa que o professor de uma determinada área de conhecimento tenha que trabalhar conceitos específicos de outras áreas; seu papel é apontar as suas possíveis relações. Essa compreensão está pouco presente em P10 e P8, uma vez que esses professores fazem referência a conceitos de outras áreas de conhecimento, no caso a Geografia e Biologia, dando a entender que seriam trabalhados por eles. Dessa forma, os investigados apresentam diversas interpretações sobre o termo interdisciplinaridade, aspecto que pode estar relacionado ao seu caráter polissêmico, presente também nos PCNs (RICARDO, 2005).

Em síntese, constatou-se que alguns professores, como P4 e P10, possuem uma compreensão sobre o trabalho temático como algo submisso aos conteúdos. Ou seja, as escolhas dos professores estão pautadas nos conteúdos escolares, muitas vezes ditados pelos livros didáticos. Isso reflete um ensino em que os assuntos levados às salas de aulas reproduzem uma visão de ciência simplificadora (MORIN, 2007), longe da complexidade necessária para compreender a realidade. Além disso, evidenciou-se que alguns professores, como P8 e P10, entendem a necessidade de trabalhos interdisciplinares, o que também representa um desafio. É interessante que os professores apontem a interdisciplinaridade como um meio 
para tratar a questão temática, no entanto, eles não explicitam maneiras e espaços para que esse processo se efetive.

\section{CONSIDERAC̣ÕES FINAIS}

Como apontam as reflexões realizadas ao longo deste trabalho, os professores possuem uma compreensão sobre as possibilidades da abordagem de temas no Ensino Médio, relacionando-a à resolução de problemas e à possibilidade de discussões sobre o desenvolvimento científico-tecnológico. Coerentes com essa compreensão, citam como temas questões pertencentes ao mundo vivencial dos alunos, ainda que não incorporem discussões de natureza mais crítica.

Constatou-se, também, que, em geral, os professores possuem clareza, dentro de uma visão simplificadora (MORIN, 2007), sobre os conteúdos que podem auxiliá-los na compreensão de determinado tema e, além disso, reconhecem a necessidade de uma abordagem interdisciplinar. Contudo, é possível identificar algumas restrições na articulação estabelecida, que parecem estar associadas à dificuldade de olhar para além dos currículos estabelecidos, ou seja, do conteúdo presente nos livros didáticos.

Esse comportamento possivelmente se deve à necessidade dos professores em cumprir o programa curricular e à dificuldade em lidar com questões complexas que remetem a um aprofundamento conceitual. Trabalhar questões complexas também requer que alterações no currículo tradicional sejam realizadas (WATANABE-CARAMELLO e KAWAMURA, 2008). Essas alterações referem-se tanto às abordagens que podem se dar de forma linear, tal como apresentada nos livros didáticos, quanto aos conteúdos e conceitos abordados que, na maioria das vezes, seguem uma estrutura rígida, em que os conteúdos científicos são tidos como "estáticos e verdadeiros", permanecendo inalterados ao longo da história. Assim, para que propostas diferenciadas sejam incorporadas na escola, é necessário que um novo posicionamento frente às questões curriculares seja tomado, em que o cumprimento de programas não seja o único norteador da formação básica.

Nesse sentido, destacam-se estudos que analisam a perspectiva da abordagem de temas como uma das possibilidades de estruturação curricular no ensino de Ciências, a exemplo de Leal e Mortimer (2008). Esses autores apontam que a abordagem de temas, em geral, tem sido aceita no contexto escolar pelos professores com a justificativa de que trabalhar com temas valoriza os conhecimentos dos alunos, proporcionando aos mesmos uma visão crítica da realidade em que vivem. Também buscando analisar os espaços escolares para a inserção de propostas centradas na articulação Freire-CTS, Strieder (2008) aponta que as escolas, em geral, estão dispostas a desenvolver propostas dessa natureza, contudo, algumas restrições se fazem presente. Dentre essas, a autora destaca a necessidade de cumprir um currículo já estabelecido, elaborado em outras instâncias.

Para uma efetiva implementação da perspectiva da Abordagem Temática, 
há necessidade de uma formação dos professores em sintonia com propostas dessa natureza. É preciso envolver os licenciandos e professores em projetos que têm como propósito o desenvolvimento e a implementação da Abordagem Temática. Nesse sentido, destacam-se projetos que foram realizados tendo como referência a perspectiva freireana, a exemplo dos fomentados por órgãos governamentais, como os realizados na Guiné Bissau/África (DELIZOICOV, 1982), no Rio Grande do Norte (PERNAMBUCO, 1983), em São Paulo/SP (SÃO PAULO, 1992) e em diversas secretarias municipais de educação de cidades brasileiras (SILVA, 2004). Também merecem destaque trabalhos que vêm sendo desenvolvidos em cursos de Formação Inicial de professores de Física, a exemplo de Watanabe-Caramelo, Strieder e Gehlen (2011) e Feistel et al.(2011).

Dessa forma, a formação de professores se dá no contexto das atividades diretamente relacionadas a sua prática pedagógica, iniciativa que cada vez mais vem permeando a formação de professores no ensino de Ciências, a exemplo dos trabalhos desenvolvidos no contexto de propostas curriculares como os estudos de Halmenschlager, Stuani e Souza (2009), Maldaner (2007), Mortimer, Machado e Romanelli (2000).

Torna-se necessário, também, discutir, na formação inicial e continuada de professores, as relações entre CTS e possibilidades de implementação desse enfoque na educação básica. $\mathrm{Na}$ análise realizada, constatou-se que os professores, mesmo não tendo um vínculo com a academia, apontam para a abordagem de questões relacionadas ao desenvolvimento científico-tecnológico, contudo apresentam algumas compreensões que necessitam ser problematizadas, como a concepção da neutralidade da ciência e a perspectiva salvacionista da CT. Essas concepções também estão presentes em outros estudos acerca de compreensões de professores que envolvem aspectos da Ciência-Tecnologia, a exemplo das pesquisas desenvolvidas por Auler (2002) e Miranda e Freitas (2008).

Outro aspecto a destacar é quanto às compreensões que os professores investigados apresentam sobre o "Por que ensinar?” e “O que ensinar?”. Quanto à primeira indagação, destaca-se que os professores expressam entendimentos que podem ser considerados distantes dos pressupostos da Abordagem Temática, principalmente por não atribuírem à possibilidade de intervenção na realidade, ou seja, por não compreenderem o caráter transformador dessa proposta no que diz respeito às percepções em relação à realidade e às atitudes de ação para efetivar as mudanças. Ao mesmo tempo, os investigados não conseguem se desprender dos currículos estabelecidos pelas escolas quando questionados sobre o que ensinar, indicando que não possuem uma compreensão clara sobre o papel que o conhecimento científico assume na Abordagem Temática, que é o de servir como meio para compreensão dos temas.

Para superar essas limitações, torna-se necessário um processo de formação inicial e continuada de professores apoiados na ideia de professor pesquisador. Nessa proposta, o docente que realiza pesquisa, por exemplo, na educação básica, enriquece os seus conhecimentos profissionais, estabelecendo uma cultura de análise da própria prática (ANDRÉ, 2001; GALIAZZI, 2003; MALDANER, 2000; 
ROSA, 2004), que necessita estar pautada na perspectiva da Abordagem Temática (DELIZOICOV, ANGOTTI, PERNAMBUCO, 2002) e do Movimento CTS (AULER, 2002; SANTOS, MORTIMER, 2002).

\section{NOTAS}

${ }^{1}$ Apoio CNPq.

2 "De acordo com essa perspectiva, o desenvolvimento científico-tecnológico, necessariamente, conduz ao progresso e ao bem estar social, pois busca, sempre, a solução para os problemas da humanidade (AULER, 2002)."

3 “Sistematizado por Delizoicov (1991) em cinco etapas: primeira (levantamento preliminar): reconhecer o ambiente em que vive o aluno. Segunda (análise das situações e escolha das codificações): escolha de situações que sintetizam as contradições vividas. Terceira (diálogos descodificadores): a partir desses diálogos se obtêm os Temas Geradores. Quarta (redução temática): trabalho de uma equipe interdisciplinar, com o objetivo de elaborar o programa e identificar quais conhecimentos disciplinares são necessários para o entendimento dos temas. Quinta (trabalho em sala de aula): desenvolvimento do programa em sala de aula."

4 "Freire (1987, p. 138), tendo como referência Goldman, identifica a consciência real efetiva como aquela pela qual "os homens se encontram limitados nas suas possibilidades de perceberem além das situações-limites".

5 “ Para Freire (1987), a consciência máxima possível é denominada como "soluções praticáveis despercebidas", categoria análoga à consciência crítica, utilizada pelo autor em produções anteriores."

\section{REFERÊNCIAS BIBLIOGRÁFICAS}

ANDRÉ, M. Pesquisa, formação e prática docente. In: M. André, (Ed.). O papel da pesquisa na formação e na prática dos professores. Campinas: Papirus, 2001.

AULER. Interações entre CTS no Contexto da Formação de Professores de Ciências. 2002. Orientador: Demétrio Delizoicov. 2002. 258 f. Tese (Doutorado) - Centro de Ciências da Educação, Universidade Federal de Santa Catarina, Florianópolis, 2002.

AULER, D.; DELIZOICOV, D. Educação CTS: Articulação entre Pressupostos do Educador Paulo Freire e Referenciais Ligados ao Movimento CTS. In: SEMINÁRIO IBÉRICO CTS NO ENSINO DAS CIÊNCIAS - LAS RELACIONES CTS EN LA EDUCACIÓN CIENTÍFICA, 4., 2006. Málaga, Anais... Málaga: ABRAPEC, 2006.

BACHELARD, G. A formação do espírito científico: contribuição para uma psicanálise do conhecimento. Trad. Estela dos Santos Abreu. Rio de Janeiro: Contraponto, 1996.

BAZZO, W. A. Ciência, Tecnologia, Sociedade: e o Contexto da Educação Tecnológica. Florianópolis: Editora da UFSC, 1998.

BRASIL. Ministério da Educação. Secretaria de Educação Média e Tecnológica. Parâmetros Curriculares Nacionais: Ciências da Natureza, Matemática e suas Tecnologias. Brasília: MEC, 2000.

Ministério da Educação. Secretaria de Educação Média e Tecnológica. PCNs+ Ensino Médio: Orientações educacionais complementares aos Parâmetros Curriculares Nacionais. Ciências da Natureza, Matemática e suas Tecnologias. Brasília: MEC, 2002. 
. Ministério da Educação. Secretaria de Educação Básica. Orientações Curriculares para o Ensino Médio: Ciências da Natureza, Matemática e suas Tecnologias. Brasília: MEC, 2006.

CARVALHO, A. M. P. A pesquisa em sala de aula e a formação de professores. In: NARDI, R. (org.). A pesquisa em Ensino de Ciências no Brasil: alguns recortes. São Paulo: Escrituras Editora, 2007.

CIRINO, M.M.; SOUZA, A.R. O discurso de alunos do ensino médio a respeito da "camada de ozônio". Ciência \& Educação, São Paulo, v. 14, n. 1, p. 115-134, 2008.

COELHO, J. C.; MARQUES, C.A. A chuva ácida na perspectiva de tema social: um estudo com professores de Química. Química Nova na Escola, São Paulo, n. 25, p.14-19, 2007.

DELIZOICOV, D. Concepscão Problematizadora do Ensino de Ciências na Educação Formal. 1982. 226 f. Dissertação (Mestrado) - Faculdade de Educação, Universidade de São Paulo, São Paulo, 1982.

DELIZOICOV, D.; ANGOTTI, J. A.; PERNAMBUCO, M. M. Ensino de Ciências: Fundamentos e Métodos. São Paulo: Cortez, 2002.

FEISTEL, R.A.B., et al. G. Abordagem Temática no Ensino de Física: Dificuldades e Contribuições. ENCONTRO DE PESQUISA EM ENSINO DE FÍSICA, 13,. 2011. Foz do Iguaçu. Anais... Foz do Iguaçu/PR: IBF, 2011.

FORGIARINI, M.S.; AULER, D. A abordagem de temas polêmicos na educação de jovens e adultos: o caso do "florestamento" no Rio Grande do Sul. Revista Electrónica de Enseñanza de las Ciencias, Vigo, Vol.8, n², 2009. FOUREZ. Crise no Ensino de Ciências?. Investigações em Ensino de Ciências. Instituto de Física UFRGS, v.8, n.2, 2003.

FREIRE, P. Pedagogia do Oprimido. 17 ed. Rio de Janeiro: Paz e Terra, 1987.

GALIAZZI, M.C. Educarpela pesquisa: ambiente de formação de professores de Ciências. Ijuí: UNIJUÍ, 2003. GARCÍA, J. E. Hacia una teoría alternativa sobre los contenidos escolares. Madrid: Díada Editora S. L., 1998. GARCİA, M. I. G.; CEREZO J. A. L.; LUJÁN, J. L. Ciencia, tecnologia y sociedad. Una introducción al estudio social de la ciencia y la tecnología. Madrid: Tecnos, 1996

GEHLEN. A função do problema no processo ensino-aprendizagem de Ciências: contribuições de Freire e Vygotsky. Orientador: Demétrio Delizoicov. 2009. 254 f. Tese (Doutorado) - Pós Graduação em Educação Científica e Tecnológica, Universidade Federal de Santa Catarina, Florianópolis, 2009.

HALMENSCHLAGER, K. R; STUANI, G. M.; SOUZA, C. A. A Situação de estudo e a Investigação Temática como possibilidades de formação continuada. In: ENCONTRO NACIONAL DE PESQUISA EM EDUCAÇÃO EM CIÊNCIAS, 7., 2009. Florianópolis. Anais... Florianópolis: ENPEC, 2009.

KRASILCHIK, M. Reformas e Realidade: o caso do ensino de Ciências. São Paulo em Perspectiva, São Paulo, v. 14, n. 1, p. 85-93, 2000

LEAL, M. C.; MORTIMER, E.F. Apropriação do discurso de inovação curricular em química por professores do ensino médio: perspectivas e tensões. Ciência \& Educação, São Paulo, v. 14, n. 2, 2008. LINDEMANN, R. H. et al. Biocombustíveis e o ensino de Ciências: compreensões de professores que fazem pesquisa na escola. Revista Electrónica de Enseñanza de las Ciencias, Vigo, v.8, n1, 342-358, 2009. Disponível em: http://www.saum.uvigo.es/reec Acesso em: 07 out. 2009.

MALDANER, O.A. A formação inicial e continuada de professores de Quimica: professores/pesquisadores. Ijuí: UNIJUI, 2000.

MALDANER, O. A. Situações de Estudo no Ensino Médio: nova compreensão de educação básica. In: NARDI, R. (org.). Pesquisa em Ensino de Ciências no Brasil: alguns recortes. Escrituras. São Paulo, p. 237-253, 2007.

MASSENA. A bistória do currículo da Licenciatura em Química da UFRJ: tensões, contradições e desafios de formadores de professores (1993-2005). Orientador: Ana Maria Ferreira da Costa Monteiro. 2010. 367 f. Tese (Doutorado) - Faculdade de Educação, Universidade Federal do Rio de Janeiro, Rio de Janeiro, 2010. MIRANDA, E.M.M.; FREITAS, D. A compreensão dos professores sobre as interações CTS evidenciadas pelo questionário VOSTS e entrevista. Alexandria Revista de Educação em Ciência e Tecnologia, Florianópolis, v.1, n.3, p.79-99, nov. 2008.

MORAES, R.; GALIAZZI, M. C. Análise Textual Discursiva. Ijuí: UNIJUÍ, 2007.

MORIN, E. Introducão ao pensamento complexo. 3 ed. Porto Alegre: Sulina, 2007.

MORTIMER, E.F.; MACHADO, A.H.; ROMANELLI, L.I. A proposta curricular de Química do Estado de Minas Gerais. Quimica Nova, São Paulo, 23 (2), p.273-283, 2000. 
PACEY, A. La cultura de la tecnología. Cidade do México: Fondo de Cultura Económica, 1990. PEDUZZI, L.O.Q.; PEDUZZI, S. S. Sobre o papel da resolução literal de problemas no Ensino de Física: Exemplos em Mecânica In: PIETROCOLA, M. (org.). Ensino de Física: conteúdo, metodologia e epistemologia em uma concepção integradora. UFSC: Florianópolis, 2001.

PERNAMBUCO, M.M.C. Projeto ensino de ciências a partir de problemas da comunidade: uma experiência no Rio Grande do Norte. Natal: UFRN, Brasília: CAPES/MEC/SPEC, 1983.

ROSA, K.; MARTINS, M.C. A inserção de história e filosofia da ciência no currículo de licenciatura em física da Universidade Federal da Bahia: uma visão de professores universitários. Investigacõoes em Ensino de Ciências, Porto Alegre, v.12, n.3, 2007. Disponível em: <http://www.if.ufrgs.br/public/ ensino/revista.htm.> Acesso em: 08 outubro 2010.

REIS, J.C.; SOUZA, S.R.; BISCH, M.S. Reconhecimento do céu na formação continuada de professores do ensino Fundamental em Ciências. In: ENCONTRO NACIONAL DE PESQUISA EM EDUCAÇÃO EM CIÊNCIAS, 6., 2007. Florianópolis. Atas... Florianópolis: ENPEC, 2007.

RICARDO. Competências, interdisciplinaridade e contextualização: dos Parâmetros Curriculares Nacionais a uma compreensão para o ensino das ciências. Orientador: Prof, Dr. Arden Zylbersztajn. 2005. 257 f. Tese ( Doutorado em Educação Científica e Tecnológica) - Universidade Federal de Santa Catarina, Florianópolis, 2005.

ROSA, M.I.P. Investigação e Ensino: articulações e possibilidades na formação de professores de Ciências. Ijuí: UNIJUÍ, 2004.

ROSA, K.; MARTINS, M.C. A inserção de história e filosofia da ciência no currículo de licenciatura em física da Universidade Federal da Bahia: uma visão de professores universitários. Investigações em Ensino de Ciências, Porto Alegre, v.12, n.3, 2007. Disponível em: <http://www.if.ufrgs.br/public/ ensino/revista.htm>. Acesso em: 04 set. 2010.

SANTOS, W.L.P.; MORTIMER, E. F. Uma Análise de Pressupostos Teóricos da Abordagem C-T-S (Ciência-Tecnologia-Sociedade) no Contexto da Educação Brasileira. Ensaio: Pesquisa em Educaşão em Ciências, Belo Horizonte, v.2, n.2, 2000, p. 133-162.

SÃO PAULO. Secretaria Municipal de Educação. Ciências: Visão da Área. Movimento de Reorientação Curricular. São Paulo: DOT/SME-SP, 1992.

SILVA, A. F. G. A construção do currículo na perspectiva popular crítica: das falas significativas às práticas contextualizadas. Orientador: Ana Maria Saul. 2004. Tese (Doutorado) - Pontifícia Universidade Católica de São Paulo, São Paulo, 2004.

STRIEDER, R.B. Abordagem CTS e Ensino Médio: Espaços de articulação. 2008. 236 f. Dissertação (Mestrado Interunidades em Ensino de Ciências) - Instituto de Física da Universidade de São Paulo, São Paulo, 2008.

STRIEDER, R. B.; KAWAMURA, M. R. Panorama das pesquisas pautadas por abordagens CTS. In: ENCONTRO NACIONAL DE PESQUISA EM EDUCAÇÃO EM CIÊNCIAS, 7., 2009. Florianópolis. Anais... Florianópolis: ENPEC, 2009.

TORRES, J. R. et al. Resignificação curricular: contribuições da Investigação Temática e da Análise Textual Discursiva. Revista Brasileira de Pesquisa em Ensino de Ciências, São Paulo, V. 8, n.2,2008.

WATANABE-CARAMELLO, G.; KAWAMURA, M.R. Inserção de temas ambientais no currículo de Física. NOVENO SIMPOSIO DE INVESTIGACIÓN EN EDUCACIÓN EN FÍSICA, 9., 2008. Rosário, AR. Anais... Rosário, AR: SIEF, 2008.

WATANABE-CARAMELLO, G.; STRIEDER, R.B; GEHLEN, S. Abordagem Temática na formação de professores de Física. In: SIMPÓSIO NACIONAL DE ENSINO DE FÍSICA, 19.,2011. Manaus. Anais... Manaus: SBF, 2011. 